\title{
Frequency of Fanconi anemia in Brazil and efficacy of screening for the FANCA 3788-3790del mutation
}

N. Magdalena ${ }^{1}$, D.V. Pilonetto ${ }^{3}$, M.A. Bitencourt ${ }^{2}$, N.F. Pereira ${ }^{3}$, R.C. Ribeiro ${ }^{4}$, M. Jeng and R. Pasquini ${ }^{2}$
${ }^{1}$ Departamento de Pediatria, ${ }^{2}$ Serviço de Hematologia e Oncologia e Transplante de Medula Óssea, Departamento de Medicina Interna, and ${ }^{3}$ Laboratório de Imunogenética, Hospital de Clínicas, Universidade Federal do Paraná, Curitiba, PR, Brasil

${ }^{4}$ Department of Hematology and Oncology, and International Outreach Program, St. Jude Children's Research Hospital, and Department of Pediatrics, College of Medicine, University of Tennessee, Memphis, TN, USA

\section{Correspondence}

R. Pasquini

Serviço de Transplante de Medula

Óssea

Hospital de Clínicas, UFPR

Rua General Carneiro, 181

80060-900 Curitiba, PR

Brasil

E-mail: tmo@hc.ufpr.br

Research partially supported by

St. Jude Children's Research

International Outreach Program and by American Lebanese Syrian Associated Charities (ALSAC),

Memphis, TN, USA.

Received May 27, 2004

Accepted December 9, 2004

....................

\begin{abstract}
Fanconi anemia (FA) is an autosomal recessive genetic disease characterized by progressive bone marrow failure, susceptibility to cancer and multiple congenital anomalies. There is important clinical variability among patients and the knowledge of factors which might predict outcome would greatly help the decision making regarding the choices of treatment and the appropriate time to start it. Future studies of the possible correlation between specific mutations with specific clinical presentations will provide the answer to one of these factors. At our Center we standardized a rapid and precise screening test using a mismatch PCR assay for a specific mutation (3788-3790del in exon 38 of gene FANCA) in Brazilian FA patients. We present the results obtained after screening 80 non-consanguineous FA patients referred from all regions of Brazil with a clinical diagnosis of FA supported by cellular hypersensitivity to diepoxybutane. We were able to detect the 3788 -3790del allele in 24 of the 80 (30\%) FA patients studied. Thirteen of the $80(16.25 \%)$ were homozygotes and 11 of the 80 $(13.75 \%)$ were compound heterozygotes, thus confirming the high frequency of the FANCA 3788-3790del mutation in Brazilian FA patients. The identification of patients with specific mutations in the FA genes may lead to a better clinical description of this condition, also providing data for genotype-phenotype correlations, to a better understanding of the interaction of this specific mutation with other mutations in compound heterozygote patients, and ultimately to the right choices of treatment for each patient with improvement of the prognosis on future studies.
\end{abstract}

Key words

- Fanconi anemia

- FANCA

- 3788-3790del mutation

- Genetic screening 


\section{Introduction}

Fanconi anemia (FA) is an autosomal recessive genetically and phenotypically heterogeneous disorder, most frequently associated with chromosomal fragility, bone marrow failure, cancer, and congenital abnormalities. These include: developmental anomalies involving mainly the head and face, skeletal malformations particularly of the radial ray, growth retardation, abnormal skin pigmentation, and renal, ocular, genital, and cardiac defects. The cardinal clinical feature is a severe progressive, life-threatening pancytopenia, and hematopoietic stem cell transplantation is the only curative method for restoring normal hematopoiesis. Somatic cell hybrid studies demonstrate that there are at least eleven complementation groups (FA-A, B, C, D1, D2, E, F, G, I, J, and $\mathrm{L})$, all of which have been connected to different genes, except B (1-4). A recent study reported that the FA-B and D1 subgroups result from hypomorphic mutation in BRCA2 (5). Mutations in a gene of the complementation group A (FANCA) accounts for $65 \%$ of all cases of the disease, with a highly heterogeneous spectrum of mutations identified throughout the gene in most populations studied. The other most frequent complementation groups are FA-G $(10-15 \%)$ and FA-C (10-15\% of the cases). The worldwide prevalence varies strongly depending on the ethnic background of each group studied (1-3).

The phenotypic heterogeneity of FA can delay or impair clinical diagnosis. The current laboratory diagnostic test consists of cytogenetic analysis looking for chromosomal breakage in response to diepoxybutane (DEB) or mitomycin $(6,7)$. Recently, a new diagnostic test was developed which assays primary lymphocytes for $F A N C D 2$ protein monoubiquitination by immunoblot. It is known that FA proteins, encoded by six cloned genes (FANCA, FANCC, FANCD2, $F A N C E, F A N C F$, and FANCG), cooperate in a common pathway to maintain genomic integrity, and that the proteins encoded by $F A N C A,-C,-E,-F$, and $-G$ form a complex culminating in the activation of FANCD2 protein into a monoubiquitinated form (1,710). The absence of the monoubiquitinated FANCD2 isoform correlates with the broad diagnosis of FA by the DEB test. A combination of retroviral gene transfer and FANCD2 protein immunoblotting provides a subtyping assay for patients newly diagnosed with FA, thus allowing the identification of the complementation group to which the patient belongs $(7,9)$.

FA is a condition involving very high risks of bone marrow failure, leukemia and solid tumors (11-14). The first event may be determined by each individual's unique combination of FA genotype, cancer susceptibility modifier genes and environmental risk factors (12). Studies are needed to quantify more precisely the individualized risk of each adverse event.

The identification of patients with specific mutations in the FA genes may lead to a better clinical description of this condition, also providing data for genotype-phenotype correlations, to a better understanding of the interaction of this specific mutation with other mutations in compound heterozygote patients, and ultimately to the right choices of treatment for each patient with improvement of the prognosis.

At our center we standardized a rapid and precise screening test for a common mutation found in Brazilian FA patients (FANCA 3788-3790del mutation) and we present the results obtained after screening a large group of patients diagnosed at the Federal University of Paraná Fanconi Anemia Center, Curitiba, PR, Brazil.

\section{Patients and Methods}

Subjects

A total of 80 non-consanguineous FA 
patients were enrolled in the study. The patients were seen at our Outpatient Clinic from August 2001 to September 2003, and were referred from all regions of Brazil to our Fanconi Anemia Center. Patient age ranged from 2 to 30 years (median age 10.4 years at the time of this test). Inclusion criteria were a clinical diagnosis of FA supported by cellular hypersensitivity to DEB and availability of adequate clinical information. A peripheral blood sample was obtained from each patient after informed consent. The study was evaluated and approved by the Ethics Committee of Hospital de Clínicas, Federal University of Paraná.

\section{Detection of 3788-3790del mutation}

A specific mismatch $\mathrm{PCR}$ restriction analysis was used to identify the 3788-3790del mutation in exon 38 of the FANCA gene in DNA extracted from peripheral blood from DEB-positive Brazilian FA patients. DNA fragments were amplified using misaligned primers and then digested with $\mathrm{MboII}$ restriction enzyme (15). The normal gene sequence contains two adjacent MboII sites and the mutant sequence contains only one of them. The reverse primer was designed so that it abolishes the most 3' end MboII site leaving the normal sequence with one site and the mutant with no MboII sites.

Normal sequence:...5'-TT^ ${ }^{\wedge} \mathrm{TTC}^{\wedge} \mathrm{CTTT}$ TCTTCTTCTCCTTGAT...

\section{3'-AAAAGGAACTA...}

Mutant sequence:...5'-TT^ ${ }^{\wedge}$ TCCTTT TCTTCTCCTTGAT...

3'-AAAAGGAACTA...

MboII recognition site (TCTTC): underlined; TCT repeat deletion: in bold ${ }^{\wedge}=$ restriction site.

Homozygotes for the $3788-3790$ deletion exhibit a 160 -bp band on a $2.5 \%$ agarose gel; heterozygotes have two bands (160 and
$130 \mathrm{bp}$, and an undetected 30-bp band) and normal individuals have only a 130-bp band and an undetected 30-bp band (Figure 1).

\section{PCR and Mboll digestion}

The sequence of the forward intronic primer is: 5'-AGGATTTATGGCCTAGAT GTAAAAA-3' (25 mer) and the sequence of the reverse primer is: 5'-GACGACAGCA GGCCCATCAAGGAAAA-3' (26 mer). The PCR procedure consisted of a $15-\mu$ l total volume of $20 \mathrm{ng}$ genomic DNA, $10 \mathrm{mM}$ Tris-HCl, pH 8.3, $1.5 \mathrm{mM} \mathrm{MgCl}_{2}, 0.25 \mathrm{mM}$ spermidine, $0.2 \mathrm{mM}$ dNTPs, $0.4 \mu \mathrm{M}$ each primer, 0.2 units of Taq DNA polymerase, and $\mathrm{H}_{2} \mathrm{O}$. The PCR conditions were: $94^{\circ} \mathrm{C}$ for $2 \mathrm{~min} ; 30$ cycles of $10 \mathrm{~s}$ at $94^{\circ} \mathrm{C}, 20 \mathrm{~s}$ at $60^{\circ} \mathrm{C}$ and $20 \mathrm{~s}$ at $72^{\circ} \mathrm{C} ; 72^{\circ} \mathrm{C}$ for $2 \mathrm{~min}$, and $4^{\circ} \mathrm{C}$ unlimited. MboII digestion: a mix of 1.4 $\mu l \mathrm{MgCl}_{2}(100 \mathrm{mM})$, at a final concentration of $10 \mathrm{mM}$, and $0.6 \mu \mathrm{l} \mathrm{MboII}(5 \mathrm{U} / \mu \mathrm{l})$ per reaction was added to the $15-\mu \mathrm{l}$ PCR product and incubated for $1 \mathrm{~h}$ at $37^{\circ} \mathrm{C}$. Three microliters of $6 \mathrm{X}$ loading dye (ethidium bromide) was added and the samples were loaded onto $2.5 \%$ agarose gel. Electrophoresis was performed in 0.5X TBE for $30 \mathrm{~min}$. The fragments were visualized under UV light and photographed.

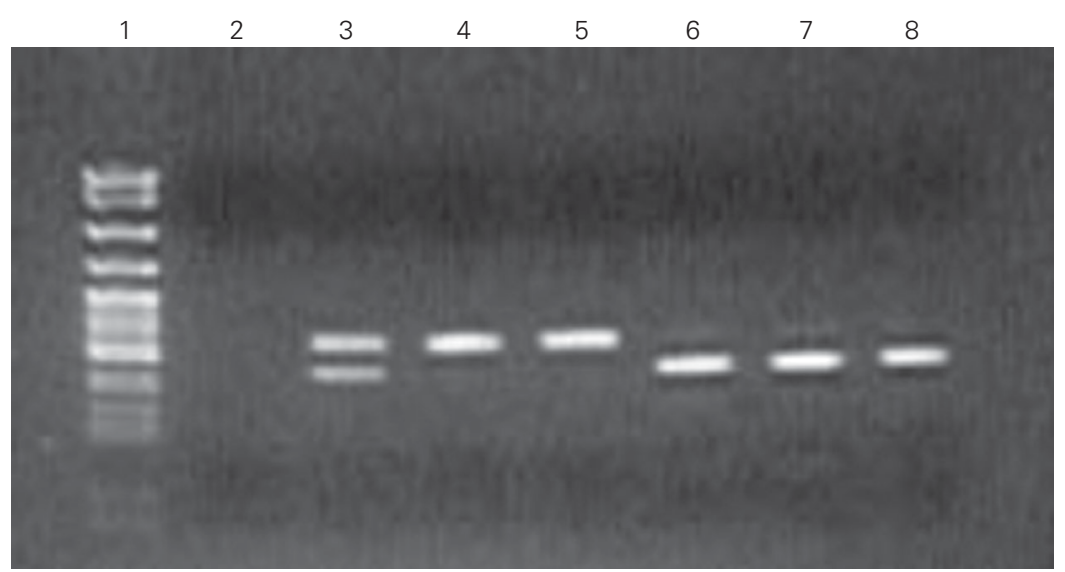

Figure 1. Screening for Fanconi anemia FANCA 3788-3790del mutation. Lane 1: pBR322; lane 2: negative control (water); lane 3: amplification of two bands of a heterozygous individual; lanes 4 and 5: amplification of the upper band of homozygous individuals; lanes 6-8: amplification of the lower band of normal individuals. 


\section{Results and Discussion}

A total of 80 DNA samples from nonconsanguineous FA patients were analyzed. Twenty-four of the 80 (30\%) FA patients studied had the 3788-3790del allele, 13 of $80(16.25 \%)$ were homozygotes and 11 of 80 $(13.75 \%)$ were compound heterozygotes, thus confirming the high frequency of the FANCA 3788-3790del mutation in Brazilian FA patients (15).

Investigation of the clinical phenotypes associated with specific mutations in FA is difficult due to the wide heterogeneity of mutations causing FA. The number of patients with the same specific mutation is generally small, and most of them are compound heterozygote individuals.

The FANCA gene is highly polymorphic, with more than 100 mutations reported, without a high frequency of a specific allele in other populations $(15,16)$. Most of the pathogenic mutations have been detected in individual patients, making carrier screening difficult, unless the proband has been genotyped for complementation group, and all 43 exons of the gene have been screened for mutations, which is a difficult and time-consuming task.

A deletion mutation in exon 38 of the FANCA gene (3788-3790del) was previously found to be present in 9 of 28 (32\%) Brazilian FA patients (17). In a study of 350 nonFANCC IFAR (International Fanconi Anemia Registry) patients the 3788-3790del mutation was found in $10 \%$ of patients and was especially common among the Brazilian patients (15).

Several studies have been done to investigate the possibility of defining risk groups in FA, especially involving the most prevalent complementation groups (FA-A, C, G), by examining the relationship between genotype and phenotype and by dividing patients into complementation or type mutation groups and then comparing the clinical phenotype of these subgroups $(1,15)$.
Analyses of the mutations found in the FANCC gene show a relatively small number of characteristic mutations which have specific ancestral origins. Mutation IVS4+4 $\mathrm{A}>\mathrm{T}$ of the FANCC gene is found in more than $80 \%$ of FA patients of Ashkenazi Jewish ancestry $(18,19)$. In Asian populations two founder mutations account for most of FANCG mutant alleles (20).

A study of the mutations found in 245 patients originating from 24 different countries showed that FA-G patients had more severe cytopenia and a higher incidence of leukemia. Somatic abnormalities were less prevalent in FA-C with a later onset of aplastic anemia, and FA-A patients homozygous for null mutations had an earlier onset of anemia and a higher incidence of leukemia than those with mutations producing an altered protein, indicating that patients with specific mutations in the FANCA and FANCG genes are in a high-risk group with a poor hematologic outcome and should be considered to be candidates both for frequent monitoring and early therapeutic intervention $(13,21)$.

It is known that $F A N C D 1$ heterozygotes have an increased risk of developing breast, ovarian and other cancers (22), and it has been speculated that heterozygous carriers of mutations in other FA genes - A, C, D2, E, $\mathrm{F}$, and $\mathrm{G}$ - may also have an increased cancer risk, perhaps depending on the presence of specific FA mutations.

In the present study, we used a mismatch PCR assay for the 3788-3790del mutation of the FANCA gene and we were able to detect this mutation in $30 \%$ of Brazilian FA patients and to establish a screening test that, besides being rapid and precise, is very useful and important for the Brazilian population.

Future studies about the correlation of the 3788-3790del mutation and the clinical outcome of the patients may lead to a better knowledge of the clinical picture of these patients and to a better understanding of the 
relationship of this specific mutation with other mutations in compound heterozygote patients. Ultimately, they would lead to the right choices of treatment for each patient with improvement of the prognosis. With a large number of patients, it may also be possible to correlate this highly expressed mutation found in the Brazilian population with phenotypic characteristics, natural history of the disease and its behavior related to bone marrow transplant procedures.

\section{Acknowledgments}

The authors thank Dr. Arleen D. Auerbach and the staff of the Laboratory of Human Genetics and Hematology, The Rockefeller University, New York, NY, for their collaboration and technical assistance in this study.

\section{References}

1. D'Andrea A \& Grompe M (2003). The Fanconi anaemia/BRCA pathway. Nature Reviews. Cancer, 3: 23-34.

2. Joenje H \& Patel K (2001). The emerging genetics and molecular bases of Fanconi anaemia. Nature Reviews. Genetics, 2: 446-457.

3. Levitus M, Rooimans MA, Steltenpool J et al. (2004). Heterogeneity in Fanconi anemia: evidence for two new genetic subtypes. Blood, 103: 2498-2503. Epub 2003 Nov. 20.

4. Levitus M (2004). Two new complementation groups identified. In: Frohnmayer L, Frohnmayer D, Eiler ME \& Owen J (Editors), FA Family Newsletter. Vol. 2. Fanconi Anemia Research Fund, Inc., Spring, OR, USA.

5. Stewart G \& Elledge SJ (2002). The two faces of BRCA2, a FANCtastic discovery. Molecular Cell, 10: 2-4.

6. Auerbach AD (1993). Fanconi anemia diagnosis and the diepoxybutane (DEB) test. Experimental Hematology, 21: 731-733.

7. Shimamura A, de Oca RM, Svenson JL, Haining N, Moreau LA, Nathan DG \& D'Andrea AD (2002). A novel diagnostic screen for defects in Fanconi anemia pathway. Blood, 100: 4649-4654. Epub 2002 Aug. 29.

8. Medhurst AL, Huber PA, Waisfisz Q, de Winter JP \& Mathew CG (2001). Direct interactions of the five known Fanconi anaemia proteins suggest a common functional pathway. Human Molecular Genetics, 10: 423-429.

9. Garcia-Higuera I, Taniguchi T, Ganesan S, Meyn MS, Timmers C, Hejna J, Grompe M \& D'Andrea AD (2001). Interaction of the Fanconi anemia proteins and BRCA1 in a common pathway. Molecular Cell, 7: 249-262.

10. Pace P, Johnson M, Tan WM, Mosedale G, Sng C, Hoatlin M, de Winter J, Joenje H, Gergely F \& Patel KJ (2002). FANCE: the link between Fanconi anemia complex assembly and activity. EMBO Journal, 21: 3414-3423.

11. Kutler DI, Auerbach AD, Satagopan J, Giampietro PF, Batish SD, Huvos AG, Goberdhan A, Shah JP \& Singh B (2003). High incidence of head and neck squamous cell carcinoma in patients with Fanconi anemia. Archives of Otolaryngology Head and Neck Surgery, 129: 106-112.

12. Offit K, Levran O, Mullaney B et al. (2003). Shared genetic suscepti- bility to breast cancer, brain tumors, and Fanconi anemia. Journal of the National Cancer Institute, 95: 1548-1551.

13. Faivre L, Guardiola P, Lewis C et al. (2000). Association of complementation group and mutation type with clinical outcome in Fanconi anemia. European Fanconi Anemia Research Group. Blood, 96: 4064-4070.

14. De Kerviler E, Guermazi A, Zagdanski AM, Gluckman E \& Frija J (2000). The clinical and radiological features of Fanconi's anaemia. Clinical Radiology, 55: 340-345.

15. Levran O, Erlich T, Magdalena N, Gregory JJ, Batish SD, Verlander $P C \&$ Auerbach AD (1997). Sequence variation in the Fanconi anemia gene FAA. Proceedings of the National Academy of Sciences, USA, 94: 13051-13056

16. Savino M, lanzano L, Strippoli $P$, Ramenghi U, Arslanian A, Bagnara GP, Joenje H, Zelante L \& Savoia A (1997). Mutations of the Fanconi anemia group A gene (FAA) in Italian patients. American Journal of Human Genetics, 61: 1246-1253.

17. Magdalena N (1999). Estudo das variações da seqüência do gene FANCA da Anemia de Fanconi. Doctoral thesis, Departamento de Genética, Universidade Federal do Paraná, Curitiba, PR, Brazil.

18. Whitney MA, Saito H, Jacobs PM, Gibson RA, Moses RE \& Grompe $M$ (1993). A common mutation in the FANC gene causes Fanconi anemia in Ashkenazi Jews. Nature Genetics, 4: 202-205.

19. Whitney MA, Jacobs P, Kaback M, Moses RE \& Grompe M (1994). The Ashkenazi Jewish Fanconi anemia mutation: incidence among patients and carrier frequency in the at-risk population. Human Mutation, 3: 339-341.

20. Yagasaki H, Oda T, Adachi D, Nakajima T, Nakahata T, Asano S \& Yamashita T (2003). Two common founder mutations of the Fanconi anemia group G gene FANCG/XRCC9 in the Japanese population. Human Mutation, 21: 555.

21. Auerbach AD, Greenbaum J, Pujara K et al. (2003). Spectrum of sequence variation in the FANCG gene: an International Fanconi Anemia Registry (IFAR) study. Human Mutation, 21: 158-168. Erratum in: Human Mutation, 22: 255.

22. D'Andrea A (2003). Fanconi anemia. Current Biology, 13: R546. 